\title{
Correction to: Time symmetry of resource constrained project scheduling with general temporal constraints and take-give resources
}

\author{
Zdeněk Hanzálek $^{1}$ (i) - Přemysl Š̉ohcha ${ }^{2}$
}

Published online: 21 November 2017

(C) Springer Science+Business Media, LLC 2017

\section{Correction to: Ann Oper Res (2017) 248:209-237 https://doi.org/10.1007/s10479-016-2184-6}

Due to some technical issues with article HTML, Algorithm 1 appeared twice and there was no ILP formulation.

Algorithm 1 at the first occurrence should be replaced with ILP formulation.

The online version of the original article can be found under https://doi.org/10.1007/s10479-016-2184-6.

\section{Zdeněk Hanzálek}

hanzalek@fel.cvut.cz

Přemysl Šůcha

suchap@ fel.cvut.cz

1 Faculty of Electrical Engineering and Czech Institute of Informatics, Robotics and Cybernetics, Czech Technical University in Prague, Technická 2, 16627 Prague 6, Czech Republic

2 Department of Control Engineering, Faculty of Electrical Engineering, Czech Technical University in Prague, Technická 2, 16627 Prague 6, Czech Republic 